\author{
Roberto Gomes Camacho; \\ (Universidade Estadual Paulista \\ Câmpus de São José do Rio Preto - UNESP) \\ Amanda D'Alarme Gimenez \\ (P G. Universidade Estadual Paulista \\ Câmpus de São José do Rio Preto - UNESP)
}

\title{
Nominalização e classe de palavras em línguas indígenas do Brasil: uma perspectiva tipológica
}

\begin{abstract}
This paper examines both the relationship between syntactic modification through the usage of relative clauses and adjectives and the morphosyntactic organization with respect to parts of speech in search for typological generalizations. In this sense, the hypothesis under investigation is the possible correlation between the absence of the adjective as a word class and the absence of relative clauses as a construction for the nominal modification. The main consequence of this correspondence is that the noun assumes the modifier function of the adjective and that the nominalized construction assumes the modifier function of the relative clause. The sample consists of 30 Brazilian indigenous languages previously described in grammar books, theses or in other descriptive materials. The data collected support the hypothesis that languages that lack adjectives as a lexical class make use of nominalization as a strategy of relativization, while languages that have adjectives in their lexicon tend to construe relative clauses through other relativization strategies.

KEYWORDS: Linguistic tipology; Relative clause; Nominalization; Parts of speech.

RESUMO: Este trabalho examina a relação entre a modificação sintática mediante o uso de orações relativas e de adjetivos e a organização morfossintática no que se refere às classes de palavras em busca de generalizações tipológicas. A hipótese que se investiga é a da possível correlação entre ausência de adjetivo como classe de palavras e ausência de oração relativa como construção a serviço da modificação nominal. A principal consequência dessa correspondência é a de o nome assumir a função modificadora do adjetivo, e a construção nominalizada, a função modificadora da oração relativa. A amostra é composta por 30 línguas indígenas brasileiras, previamente descritas em gramáticas, teses ou em outros materiais descritivos. Os dados coletados confirmam a hipótese de que as línguas que carecem de adjetivos como classe lexical se valem de nominalização como estratégia de relativização, ao passo que as línguas que dispõem de adjetivos em seu léxico tendem a construir orações relativas por meio de outras estratégias de relativização.
\end{abstract}

PALAVRAS-CHAVE: Tipologia linguística; Oração relativa; Nominalização; Classes de palavras. 


\section{Definindo o objeto e a amostra}

O fenômeno da modificação oracional ocupa um espaço proeminente nos estudos tipológicos, em que desponta o trabalho pioneiro de Keenan e Comrie (1977), um dos mais influentes sobre as condições gramaticais que restringem a acessibilidade à relativização.

Embora as línguas contenham diferenças com base nas diversas dimensões de sua organização estrutural, elas não deixam também de compartilhar categorias, relações e propriedades. Esse tipo de pesquisa tipológica, que pode conduzir ao reconhecimento de propriedades universais, é o domínio em que também se enquadra este trabalho, cujo objetivo mais geral é estabelecer uma correlação entre a nominalização como estratégia de relativização e a presença ou não da classe dos adjetivos.

Com base em estudo envolvendo uma amostra de dezoito línguas nativas da Amazônia brasileira, Camacho (2012) enfocou o domínio funcional da modificação, que, nas línguas indo-europeias, é, em geral, codificado por uma oração relativa. Divergindo dessa tendência, os resultados apontam para o uso da nominalização como alternativa de relativização em vez de uma verdadeira oração relativa em dez das dezoito (55\%) línguas investigadas.

Segundo Camacho (2012), o uso da nominalização é uma evidência de que essas línguas não dispõem de uma forma específica de oração, mas de um tipo alternativo de construção mais integrada morfossintaticamente para abranger semanticamente o domínio funcional da modificação nominal.

Outro dado relevante é que, dessas dez línguas, sete não dispõem de adjetivo como classe de palavras. Essa situação conduz à suspeita de haver uma correlação entre dois diferentes subsistemas linguísticos nas línguas da amostra, o domínio da categorização lexical e o domínio da modificação oracional.

Em razão disso, o presente trabalho se debruça sobre o estudo da modificação complexa mediante o uso de orações relativas e suas formas alternativas, como a nominalização, em comparação com o tipo de modificação não complexa que se manifesta via adjetivo. Além disso, examina a organização morfossintática de cada língua no que se refere às classes de palavras, buscando estabelecer uma relação entre a classe e a estratégia de relativização com base no estudo de Gimenez (2011), que abordou o mesmo assunto, aplicando-se às mesmas trinta línguas indígenas do Brasil de diversas famílias que servem de amostra a este trabalho.

A hipótese aqui investigada está centrada na existência de uma possível correspondência entre ausência de adjetivo como classe de palavras e ausência de oração relativa como construção a serviço da modificação nominal. A principal consequência dessa correspondência está no fato de o nome assumir o tipo de função modificadora própria do adjetivo e a construção nominalizada, a função modificadora própria da oração relativa. É na investigação dessa hipótese que está a principal justificativa teóricometodológica deste trabalho.

$\mathrm{O}$ enfoque aqui defendido assume que se deve definir o domínio funcional da modificação com base num critério amplo de aplicabilidade universal, como o resultado direto na comparação translinguística típica da abordagem funcional-tipológica. O principal postulado subjacente a essa abordagem é o de que a variação estrutural apresentada pelas línguas do mundo é sistematicamente ordenada e pode ser descrita em termos de um conjunto de condições ou princípios restritivos com validade universal. 
Um tipologista funcionalmente orientado assume que há motivações sistemáticas, sujeitas a princípios regulares subjacentes à conexão entre funções discursivas e estruturas morfossintáticas relevantes (Dik 1997a, 1997b; Hengeveld; Mackenzie 2008). A ideia básica é a existência de interconexões entre as estruturas morfossintáticas e suas funções semânticas e pragmáticas que são postuladas como inerentes à gramática de falantes individuais, entendida como o conhecimento mental do indivíduo, e o que é usualmente chamado de função externa, relacionada ao uso, à aquisição e ao processamento da linguagem. Essa perspectiva é particularmente evidente também em Bybee (1985); Givón (1990) e Croft (2000).

O enfoque funcionalista que se adota neste trabalho é essencialmente empírico, e a análise que se faz dos dados coletados tem base na comparação translinguística. Esse procedimento indutivista é tanto uma imposição teórica quanto metodológica, pois há pouco conhecimento disponível sobre os aspectos específicos das línguas, como a correlação entre classes de palavras e estratégias de relativização, o que dificulta a formulação de hipóteses preliminares, para, posteriormente, confirmá-las ou não com base nos dados levantados. Em relação ao suporte teórico, este trabalho tem como ponto de partida os resultados tipológicos já encontrados em pesquisas anteriores, como as de Keenan e Comrie (1977); Givón (1990) e Hengeveld (1992).

Para examinar a correlação entre nominalização e adjetivos no domínio funcional da modificação, a investigação de que se deriva este trabalho se debruçou sobre uma amostra de trinta línguas. O material está disposto no Quadro 1, que permite visualizar a família, a língua e a gramática respectiva.

Quadro 1: Línguas da amostra

\begin{tabular}{|l|l|l|}
\hline Família $^{1}$ & Língua & Obra de referência \\
\hline língua isolada & kwazá & Voort (2004) \\
\hline língua crioula & karipuna-crioula & Tobler (1983) \\
\hline aruak & apurinã & Facundes (2000) \\
\hline & tariana & Aikhenvald (2003) \\
\hline & warekena & Aikhenvald (1988) \\
\hline arawá & paumari & Chapman (1991) \\
\hline & jarawara & Dixon (2004) \\
\hline karib & apalaí & Koehn e Koehn (1986) \\
\hline & hixkaryana & Derbyshire (1979) \\
\hline & ingarikó & (Cruz 2005) \\
\hline & macuxí & Abbott (2001) \\
\hline & waiwai & Hawkins (1998) \\
\hline maku & hupda & Epps (2005) \\
\hline
\end{tabular}

${ }^{1}$ A classificação genética das línguas deste trabalho segue a indicação de Rodrigues (2002). 
CAMACHO \& GIMENEZ: NoMinaLIZAÇÃo E CLASSE DE PALAVRAS EM LÍNGUAS INDÍGENAS DO ...

\begin{tabular}{|l|l|l|}
\hline & dâw & Martins (2004) \\
\hline mura & pirahã & Everett (2002) \\
\hline nambikwara & nambikwara & Kroeker (2003) \\
\hline & sabanê & Araújo (2004) \\
\hline pano & matis & Ferreira (2005) \\
\hline & shanenawa & Cândido (2004) \\
\hline tukano & tukano & Ramirez (1997) \\
\hline txapakura & wari & Everett e Kern (1997) \\
\hline yanomami & sanumá & Borgman (1990) \\
\hline tronco macro-jê & & \\
\hline macro-jê bororo & bororo & Crowell (1979) \\
\hline macro-jê jê & apinayé & Oliveira (2005) \\
\hline macro-jê timbira & canela-krahô & Popjes e Popjes (1986) \\
\hline tronco tupi & & Kakumasu (1986) \\
\hline tupi-guarani & guajá & Gomes (2006) \\
\hline & kaiwá & Magalhães (2007) \\
\hline & kamayurá & Cardoso (2008) \\
\hline & urubu-kaapor & Seki (2000) \\
\hline & & Kunduruku \\
\hline
\end{tabular}

Sobre a constituição de amostras tipologicamente válidas, Rijkhoff; Bakker; Hengeveld; Kahrel (1993) afirmam que um procedimentoi enviesado pode afetar os resultados da pesquisa em diferentes graus. Os tipos mais importantes de viés envolvem proximidade genética, tipológica, geográfica e cultural entre as línguas.

De todos os vieses, o que tem consequências mais danosas é o do relacionamento genético: se as línguas têm filiação genética, é provável que herdem tipos linguísticos comuns da língua ancestral, falada na mesma área, por pessoas que compartilham a mesma cultura. Por essa razão, as propostas mais recentes de amostragem geralmente tentam desenvolver métodos que contornem o risco de viés genético, caso deste trabalho, cujo procedimento envolveu o número maior possível de famílias de línguas, sem relacionamento genético próximo.

Para desenvolver seus objetivos a seguir, este artigo se organiza em torno de quatro seções: as seções 2 e 3 tratam da literatura tipológica sobre estratégias de relativização e classes de palavras, respectivamente; a seção 4 apresenta os resultados nas línguas da amostra; a seção 5 finaliza o trabalho com generalizações referentes à correlação entre estratégias de relativização e a acessibilidade das línguas à classe lexical dos adjetivos. 


\section{As estratégias de relativização na pesquisa tipológica}

De um ponto de vista formal, há dois tipos de construção relativa, dependendo de onde se aloja o núcleo ou termo pivô (Vries 2002): dentro ou fora da oração dependente. O primeiro tipo é conhecido como relativa de núcleo interno (1a), enquanto o segundo tipo é referido como relativa de núcleo externo. O português é um exemplo de língua com relativa de núcleo externo (1b).

As relativas de núcleo externo se classificam ainda em dois tipos: de núcleo pré-nominal ou de núcleo pós-nominal. Se a oração restritiva segue o núcleo nominal, como o português em (1b), a oração relativa de núcleo externo é pós-nominal, mas se a oração restritiva precede o núcleo nominal, ela é conhecida como de núcleo externo pré-nominal, como ocorre com o japonês no exemplo (1c).

(1) a. Bambara (Keenan; Comrie 1977: 65)

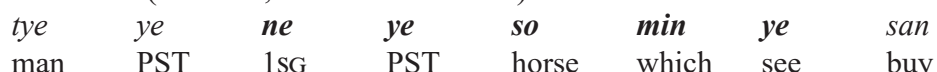

man PST ISG PST horse which see buy

'The man bought the horse that I saw.'( $O$ homem comprou o cavalo que eu vi)

b. A moça que venceu a prova de nado livre tem chance de ganhar o ouro.

c. Japonês (Keenan; Comrie 1977: 72)

[yamada san-ga ka't-te i-ru ] sa'ru

[Yamada Mr.-SBJ keep-ART be-PRES ] monkey

'The monkey which Mr. Yamada keeps' (o macaco que o Sr. Yamada mantém)

d. Japonês (Keenan; Comrie 1977 :72)

yamada san-ga sa'ru o ka't-te i-ru

Yamada Mr.-SBJ monkey OBJ keep-ART be-PRES

'Mr. Yamada keeps the monkey.' ( O Sr. Yamada mantém o macaco)

A oração restritiva em (1c) perde o objeto direto original sa'ru 'macaco' e a marcação de caso acusativo $o$, que está destacada em negrito na oração simples de (1d); (1c) não contém, portanto, nenhum traço formal explícito do SN na função de objeto direto.

Há, adicionalmente, o tipo correlativo que se vê em (2).

(2) Hindi (Song 2001: 215)

$\begin{array}{llllll}\text { jis } & a: d m i & k a & k u t t a & \text { bema:r } & \text { hai, } \\ \text { CORR } & \text { man } & \text { GEN } & \text { dog } & \text { sick } & \text { is } \\ \text { us } & a: d m i & k o & m a i & n e & \text { dekha } \\ \text { DEM } & \text { man } & \text { OBJ } & \text { 1SG } & \text { ERG } & \text { saw }\end{array}$

'I saw the man whose dog is sick' (Eu vi o homem cujo cachorro está doente)

(Lit: 'Which man's dog is sick, that man I saw')

${ }^{2} \mathrm{O}$ pivô é o constituinte semanticamente compartilhado tanto pela oração matriz quanto pela oração relativa (Vries 2002) 
Nesse exemplo do hindi, língua da Índia, derivada do sânscrito, o marcador correlativo em negrito, especificamente usado em orações relativas, identifica a:dmi 'homem', também destacado em negrito, como o núcleo nominal da dependente, que aparece em forma lexical plena na oração matriz imediatamente seguinte; em consequência, é morfossintaticamente frouxa a ligação entre a oração matriz e a dependente.

Na visão de Vries (2002), se o pivô se manifesta dentro da oração matriz, ele pode ser reconhecido como um antecedente e, nesse caso, é a relativa que contém uma lacuna, que pode ser preenchida por um pronome relativo; esse caso identifica a relativa de núcleo externo. Se o pivô é pronunciado dentro da relativa, é a oração matriz que contém a lacuna, que é preenchida pela relativa como um todo; esse caso identifica a relativa de núcleo interno. Se a relativa é anteposta, o pivô é representado por um demonstrativo, situação que identifica um tipo correlativo de oração relativa.

Há, em geral, muita variação transsistêmica em relação ao modo como se exprime o núcleo na oração restritiva, configurando um importante parâmetro tipológico (Comrie 1989). Essas diferenças são comumente referidas na literatura como "estratégias de relativização" (Keenan e Comrie 1977; Keenan 1985; Comrie 1989).

Keenan e Comrie (1977) reconhecem que há no mínimo quatro diferentes estratégias: (i) a de retenção pronominal (ii) a de lacuna (iii) a de pronome relativo e (iv) a de não redução. A quarta estratégia, que se refere à expressão completa do núcleo nominal na oração restritiva, corresponde a construções de núcleo interno e à correlativa, já mencionados anteriormente.

A estratégia de retenção pronominal ${ }^{3}$ envolve o uso de um pronome pessoal na oração restritiva, que é correferente ao núcleo nominal na oração principal; nesse caso, recupera-se a referência ao constituinte pivô ou núcleo nominal da oração matriz numa forma pronominal da oração relativa, como se vê no exemplo (3) do gilbertês, língua das ilhas Gilbert, da família austronésia, falada no Pacífico.

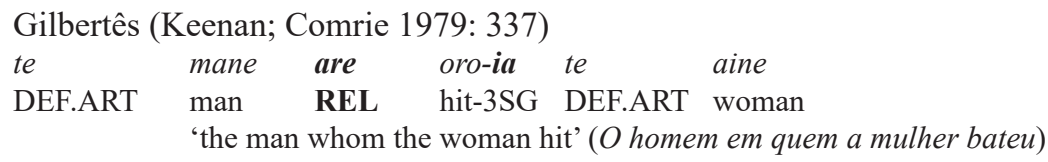

Na estratégia de lacuna, não há qualquer expressão do núcleo nominal na oração restritiva. $\mathrm{O}$ japonês é um bom exemplo de língua que usa essa estratégia, já mostrada antes em (1c), mas ela aparece também em todas as posições relativizadas do português, especialmente as de sujeito (1b) e de objeto.

Emprega-se a estratégia de pronome relativo quando se usam pronomes especiais, em geral formalmente relacionados a expressões demonstrativas, e/ou pronomes interrogativos, para representar o papel do núcleo nominal na oração restritiva com marcação de caso sintático. Encontra-se mais frequentemente essa estratégia em línguas europeias e, no português, pelo menos nos registros mais formais, conforme se vê em (4).

${ }^{3}$ Ocioso dizer que o português dispõe dessa estratégia, denominada 'relativa copiadora' por Tarallo (1983), que é ilustrada pelo exemplo contido em O ministro que o deputado não quis revelar o nome dele, cuja alternativa mais aceitável na fala distensa é a chamada relativa 'cortadora' O ministro que o deputado não quiser revelar o nome, que contém um zero anafórico na posição do pronome. 
(4) O ministro a quem o jornalista se referiu está envolvido no escândalo.

A expressão da oração relativa por nominalização, estratégia não reconhecida por Keenan e Comrie (1977), de maneira geral, ocorre mediante o acréscimo de um sufixo nominal ao verbo. A construção nominalizada (um nome derivado) passa, então, a exercer a mesma função modificadora de uma oração relativa, conforme se vê no turco (5).

(5) Turco (Givón 1990: 664)

$\begin{array}{lll}e v-i \quad g o ̈ r-e n & \text { adam } \\ \text { house-ACC } & \text { see-SG.NMLZ man } \\ \text { 'the man who saw the house'( } O \text { homem que viu a casa.) }\end{array}$

Como este trabalho, por sua vocação tipológica, vale-se de um olhar mais amplo da relativização, leva-se em conta o leque de estratégias proposto por Givón (1990), para o qual a nominalização é de fato uma estratégia formal.

Acompanhando o postulado de Givón (1990), afirma Noonan (1997) que as línguas da família tibetano-birmanesa dispõem de nominalizações como estratégias de relativização. Além das funções já esperadas, como, por exemplo, a de reificação de eventos e processos e a expressão de argumentos em orações, as nominalizações frequentemente exercem função modificadora.

A inclusão da nominalização, entre as estratégias de relativização postulada por Givón (1990) e Noonan (1997), associada aos resultados previamente obtidos no estudo de Camacho (2012) e de Oliveira e Camacho (2013), permitem postular, com segurança, que a nominalização constitui uma estratégia válida de formação de relativas.

\section{Uma perspectiva tipológica das classes de palavras predicadoras}

Como este trabalho pretende examinar a possível compatibilidade entre ausência de construção adjetiva e ausência de adjetivo como classe de palavras, é crucial assumir também um enfoque tipológico para o domínio funcional das classes de palavras, especialmente as que interessam diretamente a este trabalho, as tipicamente predicadoras na visão de Hengeveld (1992): verbo, nome, adjetivo e advérbio.

Os procedimentos adotados mais recentemente por Hengeveld e Mackenzie (2008) para identificar essas classes de lexemas se assentam em critérios semânticos (representar uma propriedade) e pragmáticos (evocar um subato discursivo). Com base nesses critérios, a classe lexical do verbo se distingue por ser núcleo de uma propriedade usada como um subato atributivo; a do advérbio, por ser núcleo de uma propriedade usada como modificador de um subato atributivo; a do nome, por ser núcleo de uma propriedade usada como um subato referencial e, finalmente, a do adjetivo, por ser núcleo de uma propriedade usada como modificador de um subato referencial. Para as classes predicadoras assim definidas, Hengeveld (1992) propõe a hierarquia contida em (6).

(6) $\quad$ verbo $>$ nome $>$ adjetivo $>$ advérbio (Hengeveld 1992: 68) 
A leitura dessa hierarquia permite predizer que a classe dos advérbios, na posição mais baixa, é mais difícil de ocorrer nas línguas do mundo que a dos verbos, que ocupa a posição mais alta. Para constituir essa hierarquia, o autor considera, primeiramente, que, como os verbos e os nomes são núcleos de seus respectivos domínios, são também elementos obrigatórios nas línguas que os contêm. Diferentemente disso, como os adjetivos e os advérbios atuam como modificadores, consistem em elementos opcionais nas línguas que os contêm; além disso, adjetivos e advérbios são definidos com base na classe de palavras a que pertence o núcleo de seus domínios, por definição, o nome e o verbo, respectivamente.

Com base nesse critério, o autor assinala que os sistemas de classe de palavras podem ser divididos em dois grandes grupos: o das línguas diferenciadas, como o português, que contam com quatro diferentes classes de palavras para exercer quatro diferentes funções; e o das línguas não diferenciadas, como o holandês, que, por disporem de uma única classe para representar as duas funções modificadoras, contam com três classes predicadoras.

As línguas não diferenciadas, que não dispõem de classes de lexemas especificamente dirigidas às funções elencadas, envolvem duas outras situações: (i) as que usam uma classe única de lexemas para mais de uma função, identificadas como flexíveis; (ii) as que se ressentem da ausência de certos itens lexicais e que, por isso, podem recorrer a soluções sintáticas compensatórias, identificadas como rígidas (Hengeveld 1992).

O tonganês, uma língua austronésia, e o tuscarora, uma língua ameríndia, são exemplos de casos extremos de língua flexível e de língua rígida, respectivamente. Para traduzir todas as funções predicadoras exercidas por verbos, nomes, adjetivos e advérbios do português, o tonganês pode empregar a mesma classe de palavras sem nenhuma adaptação morfológica. Já o tuscarora, que dispõe apenas da classe dos verbos, precisa fazer uma predicação do tipo ele é jovem para traduzir o que se denota, em português, por menino. Em outros termos, o tuscarora, um tipo extremamente rígido de língua, tem que adaptar a um predicado verbal os demais tipos de predicados.

Diferentemente da posição de Hengeveld (1992), Dixon (2006) reconhece que as línguas devem dispor de três grandes classes lexicais - nomes, verbos e adjetivos -, já que, para ele, advérbios não constituem uma classe isolada de lexemas, mas um tipo específico de adjetivo.

O conceito formulado por Dixon (2006) para o adjetivo leva em conta seu sentido descritivo com o descarte de outros tipos de modificadores nominais, como demonstrativos e interrogativos. $\mathrm{O}$ autor assume que é possível distinguir uma classe para esses modificadores em cada língua do mundo, mesmo que seus elementos compartilhem características gramaticais com nomes e verbos.

Como a hipótese sustentada por Dixon (2006) é a de que todas as línguas devem distinguir adjetivos em seu léxico, assim como distinguem verbos de nomes, segundo seus critérios, parece impossível existir uma língua que não disponha de adjetivos como classe de palavras, hipótese que, todavia, não se sustenta, como se verá adiante. Seu argumento se apoia no fato de ser mais difícil reconhecer essa classe, bem como propor generalizações sobre ela, motivos pelos quais se explicaria a ausência de adjetivos como classe em línguas estudadas por outros autores. Além disso, os advérbios de modo, considerados lexemas predicadores prototípicos por Hengeveld (1992), são considerados adjetivos por Dixon (2006), justificando-se, assim, não haver relevância teórica para a identificação de uma classe separada para esses lexemas. 
Olhando para línguas diferenciadas como o inglês e o português, todavia, é indefensável a posição de Dixon (2006), uma vez que badly se deriva de bad em inglês, do mesmo modo que, em português, por exemplo, calmamente se deriva de calmo, derivação que se estende a outros casos na língua. Seria econominamente inviável uma regra disfuncional de derivação lexical.

Para Dixon (2006), o que pode influenciar o reconhecimento de adjetivos como classe majoritária é a noção inicial que muitos pesquisadores têm de que adjetivos e nomes têm características morfológicas muito próximas, tais como marcação de gênero, número e caso. Por essa razão, não parece pouco provável que eles se pareçam com os verbos em algumas línguas e apresentem marcações típicas de verbos, tais como tempo, modo e aspecto. É por causa dessa similaridade que, segundo Dixon, muitos autores tratam os adjetivos como verbos do tipo descritivo, como o faz Seki (2000) para o kamayurá, relutando em aceitá-los como uma classe de palavras independente para classificá-los como uma subclasse verbal.

\section{A nominalização e o sistema de classes de palavras: resultados e generalizações}

Para a análise das línguas da amostra, toma-se como ponto de partida metodológico a consideração do adjetivo como classe somente nas circunstâncias em que esse fato é estabelecido como tal pelos autores das gramáticas. Mutatis mutandis, quando considerados pelos autores das gramáticas uma subclasse dos verbos, os modificadores não são enquadrados aqui na classe dos adjetivos. A explicação para isso encontra respaldo no fato de que os chamados "verbos-adjetivos" não exercem a função de modificadores simples, já que necessitam passar por um processo de predicação.

Levantaram-se, inicialmente, exemplares de orações relativas, identificandose, na sequência, as relações modificadoras de acordo com as estratégias postuladas por Keenan e Comrie (1977) e Givón (1990), a saber: de lacuna, de retenção de pronome, de pronome relativo, de não redução e as duas estratégias menos recorrentes tipologicamente, nominalização e parataxe, que, talvez por isso, sejam mais empregadas como estratégias secundárias. ${ }^{4}$

Identificar as quatro classes de palavras - verbo, nome, adjetivo e advérbio -, em especial a dos adjetivos, foi fundamental para a investigação da hipótese, que se baseia numa possível correlação entre léxico e morfossintaxe, quando a serviço da modificação nominal. O estudo da classe dos adjetivos conduziu à análise dos advérbios, principalmente porque há línguas na amostra que não dispõem de adjetivos, mas de advérbios, fenômeno que contraria a hierarquia das classes predicadoras na proposta de Hengeveld (1992).

\footnotetext{
${ }^{4}$ Deve-se lembrar aqui, de passagem, que, segundo Meira (2003), a justaposição ou parataxe é a estratégia diacronicamente primitiva nas línguas karib. A nominalização apareceu depois, especialmente nas línguas da Venezuela, fora das fronteiras da Amazônia brasileira
} 
CAMACHO \& GIMENEZ: NOMINALIZAÇÃO E CLASSE DE PALAVRAS EM LÍNGUAS INDÍGENAS DO ...

Embora a nominalização não tenha sido considerada uma típica estratégia de relativização para muitos autores, ela é considerada, neste trabalho, como uma alternativa para a ausência de uma construção tipicamente oracional. Como era previsível encontrar essa alternativa na amostra, foi importante verificar em quantas línguas ocorreu, buscando comparar a frequência de nominalização em relação às demais estratégias e, ao mesmo tempo, estabelecer uma correlação entre a existência de nominalização e o sistema de classes de palavras da língua em questão.

A análise das orações relativas na amostra conduz à formulação do quadro 2, que mostra a distribuição das estratégias encontradas: nominalização (nomin.), de lacuna (lacuna), não redução (n-red.) e de pronome relativo (p. relat.).

Quadro 2: Estratégias de relativização

\begin{tabular}{|c|c|c|c|c|c|}
\hline \multirow[t]{2}{*}{ Tronco/família } & \multirow[t]{2}{*}{ Língua } & \multicolumn{4}{|c|}{ Estratégias de relativização } \\
\hline & & nomin & lacuna & n- red & p.relat \\
\hline língua isolada & kwazá & + & & & \\
\hline língua crioula & karipuna-crioula & & & & + \\
\hline \multirow[t]{3}{*}{ aruak } & apurinã & + & & & \\
\hline & tariana & + & + & & \\
\hline & warekena & & + & & \\
\hline \multirow[t]{2}{*}{ arawá } & paumari & & + & & \\
\hline & jarawara & & + & & \\
\hline \multirow[t]{5}{*}{ karib } & apalaí & + & & & \\
\hline & hixkaryana & + & & & \\
\hline & ingarikó & + & & & \\
\hline & macuxi & + & & & \\
\hline & waiwai & + & & & \\
\hline \multirow[t]{2}{*}{ maku } & hupda & + & & & \\
\hline & dâw & & + & & \\
\hline mura & pirahã & & + & + & \\
\hline \multirow[t]{2}{*}{ nambikwara } & nambikwara & & + & & \\
\hline & sabanê & + & & & \\
\hline \multirow[t]{2}{*}{ pano } & matis & + & & & \\
\hline & shanenawa & & + & + & \\
\hline tukano & tukano & + & & & \\
\hline txapakura & wari & & & & + \\
\hline yanomami & sanumá & & & + & \\
\hline \multicolumn{6}{|l|}{ tronco macro-jê } \\
\hline macro-jê bororo & bororo & & + & & \\
\hline macro-jê jê & apinayé & + & & + & \\
\hline macro-jê timbira & canela-krahô & & & & + \\
\hline
\end{tabular}




\begin{tabular}{|c|l|c|l|l|l|}
\hline tronco tupi & & & & & \\
\hline tupi munduruku & munduruku & + & & & \\
\hline tupi-guarani & guajá & + & & & \\
\hline & kaiwá & + & & & \\
\hline & kamayurá & + & & & \\
\hline & urubu-kaapor & + & & & \\
\hline
\end{tabular}

A leitura desse quadro permite afirmar haver uma tendência nas línguas para a existência de apenas uma estratégia de relativização, uma vez que somente quatro línguas (shanenawa, pirahã, tariana e apinayé) dispõem de duas construções alternativas. Considerando troncos e famílias com três ou mais línguas, é possível constatar que a família karib e o tronco tupi são dois grupos com nominalização consistente e que a arawá e a maku são as duas famílias com lacuna consistente; as famílias aruak e nambikwara dispõem de nominalização e alguma outra estratégia secundária. O menos consistente é o tronco macro-jê, que é representada por três línguas na amostra, cada qual de família diferente, dispondo de sua própria estratégia.

É importante mencionar que, além das estratégias contidas no quadro 2, algumas línguas também se valem de parataxe ou justaposição. ${ }^{5}$ É possível observar esse fenômeno, principalmente nas línguas da família karib, em que todas se valem da nominalização, acrescida de justaposição como recurso alternativo.

As orações relativas em apalaí, uma língua karib, ocorrem basicamente por meio de nominalização (7). Há, no entanto, o procedimento de justaposição de SNs em uma relação paratática com quebra entoacional em sentenças descritivas, que geralmente envolvem orações equativas (8). ${ }^{6}$

(7) Apalaí (Koehn; Koehn 1986: 91)

j-eky wo-hpono komo

1-pet.POSS shoot-NMLZ.PST INDF

'The one who shot my pet.'(Aquele que atirou no meu animal de estimação.)

(8) Apalaí (Koehn; Koehn 1986: 75)

mame kanawa aro-ko repe zakare konõto rokene

then canoe take-ASP but alligator large only

'Then he took a canoe which was only a large alligator but (it functioned as a canoe)'.

(Então ele pegou uma canoa que era apenas um grande jacaré, mas (ele funcionava como uma canoa).

${ }^{5}$ A estratégia paratática não consta nos quadros desta seção por ser considerada uma estratégia marginal e por não funcionar como estratégia secundária em nenhuma das línguas da amostra. Além disso, seu emprego como estratégia nas línguas da amostra é bem menos frequente do que a nominalização e quase sempre essa estratégia mantém relação direta com a nominalização, ocorrendo em associação a ela.

${ }^{6}$ Deve-se lembrar aqui, de passagem, que, segundo Meira (2003), a justaposição ou parataxe é a estratégia diacronicamente primitiva nas línguas karib. A nominalização apareceu depois, especialmente nas línguas da Venezuela, fora das fronteiras da Amazônia brasileira. 
Quanto à estratégia utilizada, a nominalização é, sem dúvida, a mais empregada pelas línguas do corpus. Do total das línguas, 60\% (18/30) se valem dessa estratégia para a formação de relativas e, em $89 \%$ (16/18) desse conjunto, a nominalização é a única estratégia disponível, constituindo exceções o apinayé, que se vale de nominalizaçao e não redução, e o Tariana, que se vale de nominalização e de lacuna.

A estratégia de lacuna é a segunda mais recorrente, já que é empregada por 30\% (9/30) das línguas da amostra, seguida da estratégia da não redução, que é empregada por $13 \%$ (4/30). A estratégia do pronome relativo é a menos recorrente, já que é representada por apenas $10 \%(3 / 30)$ do total.

Um exemplo de estratégia de lacuna foi fornecido por Cândido (2004: 187) na gramática do shanenawa. O exemplo (9) mostra não haver um morfema que estabeleça uma ligação entre a oração matriz e a dependente.

(9) Shanenawa (Cândido 2004:187)

$\begin{array}{lllll}\text { saw in } & \text { naka-a } & \text { in } & \text { asfua } & \text { isin- } a-k i \\ \text { osso } 1 & \text { morder-PST } & \text { 1.POSS } & \text { boca } & \text { machucar-PST-DECL }\end{array}$

'O osso que eu mordi machucou minha boca.'

Um exemplo da estratégia de não redução ocorre no sanumá, conforme se vê em (10). Caracteriza-se pela expressão completa do núcleo nominal na oração relativa. Com efeito, ipa ulu kökö lole ĩ apresenta núcleo interno ipa ulu 'meu filho' e marca de correferencialidade $(k o ̈ k o ̈)$ externa à oração dependente, na qualidade de um operador gramatical afixado ao verbo:

(10) Sanumá (Borgman 1990: 133)

\begin{tabular}{|c|c|c|c|c|c|c|}
\hline ipa ulu & 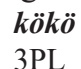 & $\begin{array}{ll}\text { lo-le } & \tilde{1} \\
\text { sit-PRES } & \text { REL }\end{array}$ & 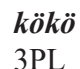 & $\begin{array}{l}h u \\
g_{0}\end{array}$ & $\begin{array}{l}m a i \\
\text { NEG }\end{array}$ & $\begin{array}{l}\text { kite } \\
\text { FUT }\end{array}$ \\
\hline
\end{tabular}

A estratégia de pronome relativo, como o nome indica, envolve o uso de pronomes relativos, que, segundo Givón (1990), não aparecem na posição relativizada, mas na fronteira entre a oração matriz e a relativa. A língua karipuna-crioula se vale dessa estratégia, como se vê em (11).

(11) Karipuna-crioula (Tobler 1983: 77)

mo wé sa fam $\boldsymbol{k i}$ te vini pase fét isi

1SG see DEM woman REL TOP come pass holiday here

'I saw that woman who had come to spend the holiday here.' (Eu vi a mulher que veio passar o feriado aqui.)

No que diz respeito às línguas que se valem de mais de uma estratégia, é interessante notar a natureza da combinação que empregam. Das quatro línguas que se valem de duas estratégias, o tariana e o apinayé empregam, além de nominalização, lacuna e não redução, respectivamente; o pirahã e o shanenawa empregam, ambas, lacuna e não redução. 
É interessante notar que, embora o pirahã e o shanenawa empreguem duas estratégias, não há restrição morfossintática ${ }^{7}$ para o emprego de uma ou outra, ou seja, sujeitos e objetos podem ser relativizados indiferentemente pelos dois recursos, situação diferente da que se apresenta para o tariana e o apinayé.

O tariana se vale de duas estratégias de relativização - lacuna e nominalização - na dependência da função sintática relativizada. Se, por um lado, o elemento relativizado for o sujeito, emprega-se o relativizador $k a$ e a estratégia de lacuna (12); se, por outro lado, as funções envolvidas forem as de objeto direto e de oblíquo, a estratégia que se usa é a nominalização (13).

(12) Tariana (Aikhenvald 2003: 538)

$\begin{array}{llll}\text { wa-phumi-se-se } & \text { ka-miña-kani } & \text { kaya } & \text { wa-na } \\ \text { 1PL-after-LOC-CONTR } & \text { REL-appear-PST.REL.PL } & \text { so } & \text { 1PL-OBJ } \\ & & & \\ \text { nu-eri } & \text { na:-mha } & & \\ \text { 1SG-younger.brother } & \text { 3PL.say:-PRES.NONVIS } & \end{array}$

'Those who had appeared after us call us young brothers.' (Aqueles que tinham aparecidodepois de nós chamam-nos de irmãos mais novos.)

(13) Tariana (aikhenvald 2003: 542)

\begin{tabular}{|c|c|c|}
\hline tuki & $d i-a$ & di-keta-pidana \\
\hline I.little & 3SG.NF-go & 3SG.NF-meet-REM.REP \\
\hline
\end{tabular}

$\begin{array}{llll}\text { iha-pidana } & \text { diha } & \text { depita } & \text { disu-nipe-pidana } \\ \text { faeces-REM.REP } & \text { ART } & \text { nigth.ADV } & \text { 3SG.NF.excrete-NMLZ-REM.REP }\end{array}$

'He (the tapir) went on a little, he encountered new faeces which were excreted (by the turtle) the same nigth.' (Ela (a anta) passou um pouco, ela encontrou novas fezes que foram excretadas (pela tartaruga) na mesma noite)

Como já mencionado, Keenan e Comrie (1977) estabelecem uma restrição universal, entendida como uma Hierarquia de Acessibilidade que se define, por seu lado, com base em relações gramaticais, que restringem os casos sintáticos passíveis de relativização: sujeito $>$ objeto direto $>$ objeto indireto $>$ oblíquo $>$ genitivo $>$ objeto de comparação (Keenan; Comrie 1977: 68). Quanto mais alta a função sintática na hierarquia mais alta a possibilidade de relativizá-la, sendo também verdadeiro o inverso.

Nos termos de Keenan e Comrie (1977), portanto, o tariana dispõe de uma estratégia primária para relativizar a função mais alta na Hierarquia de Acessibilidade e de uma estratégia secundária para codificar funções mais baixas.

Em apinayé, como mostram os exemplos (14-15), sujeito e objeto indireto são relativizados por nominalização e sujeito e objeto direto, por não redução. Nesse caso, a posição mais alta $^{8}$ da Hierarquia de Acessibilidade pode ser relativizada por ambas as estratégias; a segunda mais alta, a de objeto direto, apenas por não redução, e a mais baixa delas, a de objeto indireto, apenas por nominalização.

\footnotetext{
${ }^{7}$ Ressalta-se que se trata de restrições de natureza morfossintática. Restrições de natureza semântica ou pragmática provavelmente podem interferir no uso de uma ou outra estratégia.

${ }^{8}$ Cf. Oliveira e Camacho (2013) para uma discussão detalhada de uma proposta de extensão da Hierarquia de Acessibilidade, que passa a mesclar funções semânticas em correspondência com as relações gramaticais, além de descartar o caráter estritamente linear da proposta de Keenan e Comrie (1977).
} 
(14) Apinayé (Oliveira 2005: 282)

ic-te a-m̃̃ bi j-arẽy ja

1-ERG 2-DAT man RP-tell.NF DEF.ART

$n a \quad t \varepsilon \quad \varnothing \quad k r i \tilde{o} \quad k a m \tilde{a} \quad p a$

RLS HAB 3 village one INSV live

'This man I'm telling you about lives in the other village. (Este homem de quem eu estou falando para vocês mora na outra vila)

(15) Apinayé (Oliveira 2005: 284)

\begin{tabular}{|c|c|c|c|c|c|c|c|}
\hline$d i$ & $k s t$ & & in-mã & $m e=k \partial d \varepsilon \check{c} \partial$ & $n$ - $\tilde{o r}$ & $\check{c} w a n$ & ja \\
\hline womal & 3.ERG & & 1-DAT & $\mathrm{INDF}=$ counterpart & RP-give & NMLZ & DEF.ART \\
\hline$n a$ & $\varnothing$ & pre & $r a$ & jã & & $t \tilde{e}$ & \\
\hline RLS & 3 & PST & ASP & yesterday & MOV & go & \\
\hline
\end{tabular}

'The woman who gave me the medication left yesterday.' (A mulher que me deu o medicamento foi embora ontem.)

Song (2001) aponta que as línguas podem relativizar formalmente apenas SNs sujeitos, como ocorre com o malaio. Para relativizar funções mais baixas da hierarquia, suprindo, assim, a carência de elementos gramaticais para a relativização dessas funções, as línguas se valem de estratégias "conspiratórias", ou seja, mecanismos gramaticais alternativos para contemplar, indiretamente, o domínio funcional das relativas. É esse o caso do tariana e do apinayé, para os quais a nominalização é a estratégia "conspiratória", um recurso para relativizar as posições mais baixas de oblíquo e objeto indireto.

Vejamos, agora, o Quadro 3, que contém a distribuição das línguas da amostra no tocante à acessibilidade delas línguas às classes predicadoras de palavras.

Quadro 3: Classes de palavras

\begin{tabular}{|l|l|c|c|c|c|}
\hline \multirow{2}{*}{ tronco/família } & \multirow{2}{*}{ língua } & \multicolumn{4}{|c|}{ classes de palavras } \\
\cline { 3 - 6 } & & verbo & nome & adjetivo & advérbio \\
\hline língua isolada & kwazá & + & + & - & + \\
\hline língua crioula & karipuna-crioula & + & + & + & + \\
\hline aruak & apurinã & + & + & - & - \\
\hline & tariana & + & + & + & + \\
\hline & warekena & + & + & + & - \\
\hline arawá & paumari & + & + & + & + \\
\hline & jarawara & + & + & + & - \\
\hline karib & apalaí & + & + & & + \\
\hline & hixkaryana & + & + & & + \\
\hline & ingarikó & + & + & \multicolumn{2}{|c|}{+} \\
\hline & macuxi & + & + & \multicolumn{2}{|c|}{+} \\
\hline & waiwai & + & + & \multicolumn{2}{|c|}{+} \\
\hline maku & hupda & + & + & + & + \\
\hline & dâw & + & + & - & + \\
\hline mura & pirahã & + & + & \multicolumn{2}{|c|}{+} \\
\hline
\end{tabular}


LIAMES 17(2)

\begin{tabular}{|c|c|c|c|c|c|}
\hline nambikwara & nambikwara & + & + & + & + \\
\hline & sabanê & + & + & - & + \\
\hline \multirow[t]{2}{*}{ pano } & matis & + & + & + & + \\
\hline & shanenawa & + & + & - & - \\
\hline tukáno & tukano & + & + & - & - \\
\hline txapakura & wari & + & + & - & - \\
\hline yanomami & sanumá & + & + & + & - \\
\hline \multicolumn{6}{|l|}{ tronco macro-jê } \\
\hline macro-jê bororo & bororo & + & + & - & + \\
\hline macro-jê jê & apinayé & + & + & - & - \\
\hline macro-jê timbira & canela-krahô & + & + & - & - \\
\hline \multicolumn{6}{|l|}{ tronco tupi } \\
\hline tupi munduruku & munduruku & + & + & - & + \\
\hline \multirow[t]{4}{*}{ tupi-guarani } & guajá & + & + & + & + \\
\hline & kaiwá & + & + & - & - \\
\hline & kamayurá & + & + & - & - \\
\hline & urubu-kaapor & + & + & - & - \\
\hline
\end{tabular}

Essa distribuição permite deduzir que todas as línguas apresentam uma classe de palavras própria para verbos e nomes, o que significa afirmar que nenhuma língua da amostra pode ser considerada um caso extremo de língua rígida. Há apenas 23\% (7/30) das línguas com as quatro classes de palavras predicadoras, consistindo, portanto, em línguas diferenciadas.

Outras 23\% (7/30), representadas por apinayé, canela-crahô, kaiwá, kamayurá, apurinã, tukano e wari, não dispõem nem de adjetivos nem de advérbios como classes de palavras.

Do conjunto de 53\% (16/30) das línguas que apresentam três classes morfológicas, $24 \%$ delas (4/16) - jarawara, sanumá, hupda e warekena - dispõem, além de verbos e de nomes, da classe dos adjetivos. Por outro lado, 38\% (6/16) dispõem somente da classe de advérbios (urubu-kaapor, munduruku, dâw, sabanê, bororo e kwazá), mas não da de adjetivos. Essas são línguas não diferenciadas e rígidas.

Outros 38\% (6/16) das línguas com três classes (apalaí, hixkaryiana, ingarikó, macuxi, waiwai e pirahã) dispõem de uma única classe lexical para representar adjetivos e advérbios; consistem, poranto em línguas não diferenciadas, mas flexíveis (Hengeveld 1992).

Também fazem parte do grupo das não diferenciadas as línguas da família karib e o pirahã da família mura que dispõem igualmente de três classes lexicais. A diferença entre elas, no entanto, consiste no fato de terem agrupadas, em uma mesma classe, os adjetivos e os advérbios, o que não se comprovou nas outras línguas da amostra. Na direção do que é proposto por Dixon (2006), a inclusão de adjetivos e advérbios na mesma classe lexical é um fato tipologicamente esperável, talvez até mesmo teoricamente mais plausível que a existência das quatro classes predicadoras postuladas por Hengeveld (1992). 
CAMACHO \& GIMENEZ: NOMINALIZAÇÃo E ClASSE DE PALAVRAS EM LÍNGUAS INDÍGENAS do ...

Por fim, são línguas diferenciadas 23\% (7/30) da amostra, ou seja, as que dispõem das quatro classes lexicais, cada qual exercendo uma diferente função predicadora.

Com essa distribuição de classes lexicais, a maioria das línguas - 80\% (24/30) - dispõe de um sistema lexical compatível com a hierarquia implicacional proposta por Hengeveld (1992): verbo > nome $>$ adjetivo > advérbio. No entanto, as línguas urubu-kaapor, munduruku, dâw, sabanê, bororo e kwazá, equivalentes a 20\% (6/30), dispõem de nome, verbo e advérbio, o que significa transpor um ponto da escala.

Voltando, agora, a atenção para a principal hipótese deste trabalho, vejamos, no quadro 4, a distribuição de adjetivos em relação à respectiva estratégia de relativização: nominalização (nomin), de lacuna (lacuna), não redução (n-red) e pronome relativo (p. rel).

Quadro 4: Presença de adjetivos e estratégias de relativização

\begin{tabular}{|c|c|c|c|c|c|c|}
\hline \multirow[t]{2}{*}{ família } & \multirow[t]{2}{*}{ língua } & \multicolumn{4}{|c|}{ estratégia de relativização } & \multirow[t]{2}{*}{ Adjetivo } \\
\hline & & nomin & lacuna & n-red & p rel & \\
\hline língua isolada & kwazá & + & & & & \\
\hline língua crioula & karipuna-crioula & & & & + & + \\
\hline \multirow[t]{3}{*}{ aruak } & apurinã & + & & & & \\
\hline & tariana & + & + & & & + \\
\hline & warekena & & + & & & + \\
\hline \multirow{2}{*}{ arawá } & paumari & & + & & & + \\
\hline & jarawara & & + & & & + \\
\hline \multirow[t]{5}{*}{ karib } & apalaí & + & & & & \\
\hline & hixkaryana & + & & & & \\
\hline & ingarikó & + & & & & \\
\hline & macuxi & + & & & & \\
\hline & waiwai & + & & & & \\
\hline \multirow[t]{2}{*}{ maku } & hupda & + & & & & + \\
\hline & dâw & & + & & & \\
\hline mura & pirahã & & + & + & & + \\
\hline \multirow[t]{2}{*}{ nambikwara } & nambikwara & & + & & & + \\
\hline & sabanê & + & & & & \\
\hline \multirow[t]{2}{*}{ pano } & matis & + & & & & + \\
\hline & shanenawa & & + & + & & + \\
\hline tukano & tukano & + & & & & \\
\hline txapakura & wari & & & & + & \\
\hline yanomami & sanumá & & & + & & + \\
\hline \multicolumn{7}{|l|}{ tronco macro-jê } \\
\hline macro-jê bororo & bororo & & + & & & \\
\hline
\end{tabular}


LIAMES 17(2)

\begin{tabular}{|c|l|c|c|c|c|c|}
\hline macro-jê jê & apinayé & + & & + & & \\
\hline macro-jê timbira & canela-krahô & & & & + & \\
\hline tronco tupi & & & & & & \\
\hline tupi munduruku & munduruku & + & & & & \\
\hline tupi-guarani & guajá & + & & & & + \\
\hline & kaiwá & + & & & & \\
\hline & kamayurá & + & & & & \\
\hline & urubu-kaapor & + & & & & \\
\hline
\end{tabular}

A leitura do quadro 4 permite afirmar que há, na amostra, uma incidência de $60 \%$ (18/30) das línguas com adjetivo como classe isolada de palavras, mas também um número razoável de 40\% (12/30) que dispõem dessa categoria lexical.

Das 18 línguas que carecem de adjetivos como classe lexical, 78\% (14/18) constroem nominalizações para exercer a função pretendida por uma relativa; duas delas, dâw e bororo, se valem da estratégia da lacuna; outras duas, wari e canela-krahô, empregam a estratégia do pronome relativo, e apenas uma, apinayé, se vale tanto de nominalização como da não redução para construir uma oração relativa.

Confirma-se, ao menos em termos quantitativos, a hipótese de que a nominalização assume a função de modificador nas línguas que carecem da classe de adjetivos. Embora quatro línguas se valham de uma estratégia alternativa, o que é menos esperado, a maioria indica que o recurso da nominalização é o mais comumente empregado quando a língua se encontra na situação mencionada. Além disso, fica confirmada a correlação entre ausência de adjetivos e presença de nominalização como estratégia de relativização.

A situação inversa, ou seja, a das línguas que apresentam adjetivos como classe lexical, também favorece a confirmação da hipótese proposta, levando em conta que, quando uma língua exerce tanto a modificação simples (por meio de adjetivos) quanto a modificação complexa (por meio de relativas), é menos provável o uso de nominalização como estratégia. Essa relação fica evidente na leitura do quadro 4, já que das 40\% (12/30) das línguas com a classe de adjetivos em seu léxico, 75\% (9/12) servem-se de uma estratégia não nominalizadora, com exceção do tariana, que se vale de duas estratégias, uma das quais, a nominalização.

No tocante às construções relativas empregadas pelas línguas que dispõem de adjetivos como classe, nota-se que a estratégia de lacuna ocorre em 58\% (7/12) das línguas, mas no tariana, como já mencionado, no shanenawa e no sanumá, esse tipo não consiste no único recurso, já que, as duas últimas dispõem também da estratégia de não redução. Nesse caso, os dados apontam para uma tendência, pelo menos em termos quantitativos, de línguas com adjetivos como classe lexical empregarem a estratégia de lacuna para a construção relativa. 


\section{Generalizações e implicações teóricas}

A nominalização se mostra um recurso versátil, capaz de representar o domínio funcional da modificação oracional e se constitui, portanto, uma estratégia alternativa de relativização. Conspiram a favor desse argumento a versatilidade do uso desse mecanismo, já apontada por Noonan (1997), a recorrência de seu uso como estratégia, para línguas da família karib, atestada por Meira (2003), e ainda o reconhecimento do uso de nominalização como estratégia em outras línguas, como em gavião de Rondônia (Moore 2006) e em sakurabiat (Galucio 2006).

Outro argumento que confere estatuto de estratégia ao recurso da nominalização se sustenta no que afirmam Shibatani e Makhashen (2009): pode-se ver a nominalização como estratégia se ela atuar, em primeiro lugar, como entidade referencial (sua função prototípica) e, em segundo lugar, como modificador, situação atestada nas línguas da amostra.

A busca pela confirmação da hipótese deste trabalho conduziu a alguns desdobramentos adicionais, que dizem respeito principalmente às classes de palavras. Não constou nos objetivos específicos deste estudo tratar particularmente dos advérbios, mas apontar a existência deles como classe, seguindo as informações contidas no material de análise e em consonância com o ponto de vista teórico adotado.

Mesmo assim, deduziu-se que faltam ainda critérios consistentes que diferenciem o adjetivo do advérbio, já que o alto grau de entrelaçamento entre eles e, por conseguinte, baixo grau de distinção categorial, torna metodologicamente complexa a tarefa de identificá-los lexicalmente. Os critérios, quando explícitos, são, muitas vezes, controversos e insuficientes para a delimitação da fronteira que os separa.

Outro aspecto instigante é o de que, quando as gramáticas examinadas fazem menção aos advérbios de modo, a avassaladora maioria aponta a existência de itens lexicais restritos que se traduzem por "vagarosamente" e "rapidamente", como os únicos representantes possíveis dessa classe. Essa incidência limitada pode estar associada à importância conferida pela cultura indígena, em termos de estilo de vida, aos verbos de movimento. Essa dedução, um tanto especulativa, está aberta, constituindo, portanto, uma possibilidade de investigação futura. No entanto, essa redução a movimento pode representar mais ausência que presença de uma classe predicadora para os advérbios de modo e, portanto, mais aspecto lexicalmente motivado do que modificação.

Uma retomada da hierarquia de classes proposta por Hengeveld (1992), contida em (6), mostra que adjetivos e advérbios ocupam as posições mais baixas, o que implica estarem mais raramente presentes nas línguas. A ideia básica dessa hierarquia é a de que verbos e nomes, posições mais altas, atuam como núcleos, enquanto adjetivos e advérbios atuam como modificadores desses núcleos: o primeiro modificando nomes e o segundo, verbos. A busca por essas categorias nas gramáticas não é tarefa descritiva simples, principalmente pela ausência de critérios consistentes que as diferenciem entre si.

Nessas circunstâncias, além da proposta de Hengeveld (1992), é possível contar com a sugestão alternativa de Dixon (2006), segundo a qual são três as grandes classes de palavras e não quatro. Dixon (2006) sustenta que não é necessário distinguir uma classe morfológica para os advérbios e que, além de nomes e verbos, as línguas devem dispor apenas de mais uma classe, a de adjetivos, em que estaria incluída a classe dos advérbios predicadores, postulada por Hengeveld (1992). 
Diante da situação que se apresenta para as classes de palavras nas línguas da amostra, propõe-se, em (16), uma hierarquia implicacional alternativa, que contenha três classes lexicais em vez de quatro.

(16) núcleo dentro de um subato atributivo (sintagma verbal) > núcleo dentro de um subato referencial (sintagma nominal) > núcleo dentro de um subato referencial e de um subato atributivo (sintagma adnominal/adverbial).

A proposta dessa hierarquia converge, por conseguinte, tanto com os postulados de Hengeveld (1992) quanto com os de Dixon (2006), contemplando-os ao mesmo tempo, ressalvadas as adaptações nela contidas. Diferentemente, no entanto, do que propõe Dixon, as três categorias relevantes na gramática de uma língua não são tratadas sob um ponto de vista estritamente lexical, mas de um ponto de vista rigorosamente funcional. Essa visão pressupõe considerar a função semântica e pragmática dos itens lexicais envolvidos, o que a aproxima da hierarquia implicacional proposta por Hengeveld (1992).

A descrição dos dados das línguas mostrou que não há problemas de distinção na fronteira entre verbos e nomes, ou seja, os traços distintivos de uma e outra classe lexical estão suficientemente claros, ao contrário das características de adjetivos e de advérbios. Nessas circunstâncias, a inclusão de adjetivos e advérbios em uma única categoria lexical fornece um olhar mais abrangente para essa hierarquia implicacional, e até mesmo com um nível mais elevado de abstração, útil para a pesquisa tipológica de classes de palavras. Além disso, a eliminação da fronteira entre adjetivos e advérbios parece traduzir mais adequadamente as observações feitas na análise particular desses elementos em cada uma das línguas da amostra, o que significa conter tanto adequação descritiva quanto adequação tipológica.

\section{$\overline{\text { Referências }}$}

Abbott, Miriam (1991). Macushi. In Desmond C. Derbyshire; Geoffrey K. Pullum (eds). Handbook of Amazonian languages, vol. 3, pp. 23-160. Berlin: Mounton de Gruyter.

Aikhenvald, Alexandra Y. (2003). A grammar of Tariana, from Northwest Amazonia. Cambridge: CUP.

Aikhenvald, Alexandra Y. (1988). Warekena. In Desmond C. Derbyshire; Geoffrey K. Pullum (eds). Handbook of Amazonian languages, vol. 4, pp. 225-439. Berlin: Mouton de Gruyter.

Araújo, Gabriel Antunes (2004). A grammar of Sabanê: a Nambikwaran language. Utrecht: LOT.

Borgman, Donald (1990). Sanuma. In Desmond C. Derbyshire; Geoffrey K. Pullum (eds.) Handbook of Amazonian languages, vol. 2, pp. 17-248. Berlin: Mounton de Gruyter.

Bybee, Joan (1985). Morphology: a study of the relation between meaning and form. Amsterdam/Philadelphia: John Benjamins.

Callow, John Campbell (1962). The Apinayé language: Phonology and grammar (Doutorado em linguística). Londres: London University.

Camacho, Roberto Gomes (2012). A nominalização como estratégia de relativização em línguas nativas da Amazônia brasileira. Luso-Brazilian Review 49 (1): 225-251. 
Cândido, Glaucia Vieira (2004). Descrição morfossintática da língua shanenawa (pano) (Tese de doutorado). Campinas: Universidade Estadual de Campinas.

Cardoso, Valéria Faria (2008). Aspectos morfossintáticos da lingua kaiowa (Guarani) (Tese de doutorado). Campinas: Universidade Estadual de Campinas.

Comrie, Bernard (1989). Language universals and linguistic typology. Oxford: Blackwell.

Chapman, Shirley; Derbyshire, Desmond C. (2000). Paumari. In Desmond C. Derbyshire; Geoffrey K. Pullum; (eds.) Handbook of Amazonian languages, vol. 3, pp. 161-352. Berlin: Mounton de Gruyter.

Croft, William (2000). Explaining language change: an evolutionary approach (Longman Linguistic Library) Harlow: Pearson Education Ltd.

Crofts, Marjorie (1973). Gramática munduruku (Série Linguística 2). Cuiabá: Summer Institute of Linguistics.

Crowell, Thomas Harris (1979). A grammar of Bororo (Tese de doutorado). Ithaca: Cornell University.

Cruz, Maria Odileiz Sousa (2005). Fonologia e gramática ingarikó (Tese de doutorado). Amsterdam: Vrije Universiteit.

Derbyshire, Desmond C. (1979). Hixkaryana (Lingua Descriptive Studies, vol. 1). Amsterdam: North-Holland Publishing Company.

Dik, Simon Charles (1997a). The theory of functional grammar. Part I: The structure of the clause. Ed. by Kees Hengeveld. Berlin/Nova Iorque: Mouton de Gruyter.

Dik, Simon Charles (1997b). The theory of functional grammar. Part II: Complex and derived constructions. Ed. by Kees Hengeveld. Berlim/Nova Iorque: Mouton de Gruyter.

Dixon, R. M. W (2006). Adjective classes in typological perspective. In Alexandra Y. Aikhenvald.; R. M. W. Dixon (eds.) Adjective classes: a cross-linguistic typology, pp. 2-49. Oxford: Oxford University Press.

Dixon, R. M. W. (2004). The Jarawara language of Southern Amazonia. Oxford: Oxford University Press.

Epps, Patience (2005). A grammar of Hupda (Tese de doutorado). Charlottesville: University of Virginia.

Everett, Daniel (1992). A lingua pirahã e a teoria da sintaxe. Descrição, perspectivas e teoria. Campinas: Editora da UNICAMP.

Everett, Daniel; Kern, Barbara (1997). Wari: The pacaas novos language of Western Brazil. London: Routledge.

Facundes, Sidney da Silva (2000). The language of the Apurinã people of Brazil (Arawak) (Tese de doutrado). Buffalo: SUNY.

Ferreira, Rogério Vicente (2001). Língua matís: aspectos descritivos da morfossintaxe (Dissertação de mestrado). Campinas: Universidade Estadual de Campinas.

Galucio, Ana Vilacy (2006). Relativização em língua sakurabiat (Mekens). Ciências Humanas 1(1): 49-59.

Gimenez, Amanda D’Alarme (2011). Estratégias de relativização e classe de palavras: um estudo tipológicofuncional (Dissertação de mestrado). São José do Rio Preto: Universidade Estadual Paulista.

Givón, T. (1990). Syntax: a functional-typological introduction. Amsterdam/Philadelphia: John Benjamins.

Gomes, Dioney Moreira (2006). Estudo morfológico e sintático da língua munduruku (Tupi) (Tese de doutorado). Brasília: Universidade de Brasília. 
Hawkins, Robert (1998). Wai wai. In Desmond C. Derbyshire; Geoffrey K. Pullum (eds). Handbook of Amazonian languages, vol. 4, pp. 25-224. Berlin: Mounton de Gruyter.

Hengeveld, Kees (1992). Non-verbal predication: theory, typology, diachrony. (Functional grammar series 15). Berlin/New York: Mouton de Gruyter.

Hengeveld, Kees; Mackenzie, John Lachlan (2008). Functional discourse grammar: a typologically based theory of language structure. Oxford: Oxford University Press.

Kakumasu, James (1986). Urubu-Kaapor. In Desmond C. Derbyshire, Geoffrey K. Pullum (eds). Handbook of Amazonian languages, vol. 1, pp. 326-403. Berlin: Mouton de Gruyter.

Keenan, Edward (1985). Relative clauses. In Timothy Shopen (ed.). Language typology and syntactic description, vol. 2, pp. 141-170. Cambridge: University Press.

Keenan, Edward; Comrie, Bernard (1977). Noun phrase accessibility and universal grammar. Linguistic Inquiry 8(1): 63-99.

Koehn, Edward; Koehn, Sally (1986). Apalaí. In Desmond C. Derbyshire; Geoffrey K. Pullum (eds). Handbook of Amazonian languages, vol. 1, pp. 33-127. Berlin: Mouton de Gruyter.

Kroeker, Barbara (1980). Aspectos da língua nambikuára. Brasília: Summer Institute of Linguistics.

Leipzig Glossing Rules (2015). Conventions for interlinear morpheme-by-morpheme glosses. Disponível em http://ww.eva.mpg.de/lingua/resources/glossing-rules.php (Acesso 10/02/2017).

Magalhães, Marina Maria Silva (2007). Sobre a morfologia e a sintaxe da língua Guajá (família tupi-Guaraní) (Tese de doutorado). Brasília: Universidade de Brasília.

Martins, Silvana Andrade (2004). Fonologia e gramática dâw. Utrecht: LOT.

Meira, Sérgio (2003). Orações relativas em línguas karib. Ciências Humanas 1(1): 105-121.

Moore, Denny (2006). Cláusulas relativas em gavião de Rondônia. Ciências Humanas 1(1): 135-143.

Noonan, Michael (1997). Versatile nominalizations. In Joan Bybee; John Haiman; Sandra A. Thompson (eds.). Essays on language function and language type, pp. 373-394. Amsterdam: John Benjamins.

Oliveira, Christiane Cunha de (2005). The language of the Apinajé people of Central Brazil (Tese de doutorado). Eugene: University of Oregon.

Oliveira, Gabriela Maria de; Camacho, Roberto Gomes (2013). Estratégias de relativização e construções alternativas nas línguas indígenas do Brasil. São Paulo: Cultura Acadêmica.

Popjes, Jack; Popjes, Jo (1986). Canela-Krahô. In Desmond C. Derbyshire; Geoffrey K. Pullum (eds.). Handbook of Amazonian languages, vol. 1, pp. 128-199. Berlin: Mouton de Gruyter.

Ramirez, Henri (1997). A fala tukano dos ye'pâ-masa. Tomo I: Gramática. Manaus: CEDEM.

Rijkhoff, Jan; Bakker Dik; Hengeveld, Kees; Kahrel, Peter (1993). A method in language sampling. Studies in languages 17: 169-203. doi: 10.1075/sl.17.1.07rij

Rodrigues, Aryon Dall'Igna (2002). Línguas brasileiras: para o conhecimento das línguas indígenas. São Paulo: Edições Loyola.

Seki, Lucy (2000). Gramática do kamaiurá. Língua tupi-guarani do Alto Xingu. Campinas: Imprensa Oficial/ Editora da UNICAMP. 
Shibatani, Masayoshi; Makhashen, Khaled (2009). Nominalization in soqotri, a South Arabian language of Yemen. In Leo Wetzels (ed.) Endangered Languages: Contributions to morphology and morpho-syntax, pp. 9-31. Leiden: Brill. Disponível em http://www.ruf.rice.edu/ eivs/papers/Soqotri\%20nominalization. pdf (Acesso 25/11/2016).

Song, Jae Jung (2001). Linguistic typology. morphology and syntax. London: Longman.

Tarallo, Fernando (1983) Relativization strategies in Brazilian portuguese (Tese de doutorado). Pennsylvania: Universidade da Pennsylvania.

Tobler, S. Joy (1983). The grammar of Karipúna creole (Série Linguística 10). Brasília: Summer Institute of Linguistics.

Voort, Hein van der (2004). A grammar of Kwaza (Mouton Grammar Library 29). Berlin: Mouton de Gruyter.

Vries, Mark de (2002). The syntax of relativization. Utrecht: LOT.

$\begin{array}{llll}\text { Abreviaturas } & & & \\ 1 & \text { first person } & \text { LOC } & \text { Locative } \\ 3 & \text { third person } & \text { MOV } & \text { Movement } \\ \text { negation, negative } \\ \text { ACC } & \text { Accusative } & \text { NEG } & \text { Nonfinite } \\ \text { ADV } & \text { adverb(ial) } & \text { NF } & \text { nominalizer/nominalization } \\ \text { ART } & \text { Article } & \text { NMLZ } & \text { non-visual sensory evidence } \\ \text { ASP } & \text { Aspect } & \text { NONVIS } & \text { Object } \\ \text { DAT } & \text { Dative } & \text { OBJ } & \text { Plural } \\ \text { DECL } & \text { Declarative } & \text { PL } & \text { Possessive } \\ \text { COLL } & \text { Collective } & \text { POSS } & \text { Present } \\ \text { CONTR } & \text { Contrastive } & \text { PRS } & \text { Past } \\ \text { DAT } & \text { Dative } & \text { PST } & \text { Participle } \\ \text { DEF } & \text { Definite } & \text { PTCP } & \text { Relational prefix } \\ \text { DEM } & \text { Demonstrative } & \text { RP } & \text { Relativizer } \\ \text { ERG } & \text { Ergative } & \text { REL } & \text { Realis } \\ \text { FUT } & \text { Future } & \text { RLS } & \text { Remote } \\ \text { GEN } & \text { Genitive } & \text { REM } & \text { Reportative } \\ \text { HAB } & \text { Habitual } & \text { REP } & \text { Subject } \\ \text { INDF } & \text { Indefinite } & \text { SBJ } & \text { Singular } \\ \text { INSV } & \text { Inessive } & \text { SG } & \text { Topic } \\ \text { INF } & \text { Infinitive } & \text { TOP } & \end{array}$

Recebido: $19 / 5 / 2017$

Revisto: $18 / 8 / 2017$

Aceito: 24/8/2017. 